\title{
Role of objectives in Dental Education - A Review
}

\section{K Chandrasekharan Nair ${ }^{1 *}$, Pradeep Dathan ${ }^{2}$, Bheemalingeswara Rao ${ }^{3}$ and Mohan Kumar $\mathbf{T}^{4}$}

${ }^{1}$ Professor Emeritus, Department of Prosthodontics, Sri Sankara Dental College,

Akathumuri, Thiruvananthapuram, Kerala, India

${ }^{2}$ Professor and Head of the Department of Prosthodontics, Sri Sankara Dental

College, Akathumuri, Thiruvavananthapuram, Kerala, India

${ }^{3}$ Professor of Prosthodontics, Vishnu Dental College, Bhimavaram, Andhra Pradesh, India

${ }^{4}$ Professor of Prosthodontics, College of Dental Sciences and Hospital, Rau, Indore, India

*Corresponding Author: K Chandrasekharan Nair, Professor Emeritus, Department of Prosthodontics, Sri Sankara Dental College, Akathumuri, Thiruvananthapuram, Kerala, India.
Received: December 27, 2021

Published: January 21, 2022

(C) All rights are reserved by

K Chandrasekharan Nair., et al.

\begin{abstract}
Dental education has a profound history both in pre and post independent India. The evolution of dental education has been mainly based traditional practices which were followed in the west. Young teachers followed their teachers and their practices. Serious research has happened in the field of dental education and teachers have realized the importance of specifying the goals of dental education; to be precise the learning goals rather than the teaching goals. Without specifying the goals and precise objectives, the progress of dental education will be like a ship without rudder in the vast ocean.
\end{abstract}

Keywords: Educational Objectives; Institutional Objective; Departmental Objective; Specific Learning Objective; Cognitive Domain; Psychomotor Domain; Affective Domain

\section{Introduction}

Swami Vivekananda said "Education is the manifestation of the divine perfection already existing in man". In other words, education is the process of facilitating learning or the acquisition of knowledge, skills, values and personal development. The main aim of education is to bring about a change in behaviour of the student within a predetermined period of time. Education is derived from four Latin words viz. Educare, Educere, Educatum and E-Duco. Educare means to train and mould or to raise and nourish. Educere means to draw out what is within. Educatum denotes the act of teaching. E-duco is the combination of two words ' $E$ ' and 'Duco' which mean to draw out the inner power of man. At the end of the educational process, an expected change in behaviour should happen. The expectation will be predetermined and will be stated as educational objectives. The objectives will be clearly understood by the teachers and the students will be made aware of this. If we do not know where we have to go, we cannot start our journey. If we are clear about our destination, we will know when we reach there. This article provides a brief description on the role of objectives in dental education. 


\section{Educational objectives}

Educational objectives are statements, which tell us what the students should be able to do at the end of the learning period that they could not do before. For example, a fresh first year BDS students may have "some" idea of dental caries. But after completion of the course, the student:

- Is able to describe how the disease appears, the causative organisms, the treatment and preventive methods.

- Is able to use a mouth mirror and probe, and can identify the disease and gauge the extent of infection.

- Is aware of the pain and discomfort dental caries can cause to a patient and shows consideration and readily offers services.

All these things the student could not do before undergoing the training. After the educational process he is able to do all these. From the teachers' point of view, they taught the students appropriately and with dedication. Beyond the satisfaction teachers receive, it was their aim that the student should learn and perform. Hence the above statements can be rightly stated as learning objectives. A teacher can take hours of lectures on the aetiologic process of dental caries. May be that was the objective of the teacher. But we will be happy if the student can list the causes of dental caries without any mistake at the end of the class. This helps the teacher to evaluate the students easily at the end of the class or the learning period.

Go through the following objective statements which are grouped into three:

\section{Group 1}

- At the end of the BDS course, the student should be able to diagnose and manage oral diseases that occur frequently in the community.

- At the end of the BDS course, the student should be able to provide preventive and curative oral health care to the individuals and community in both the healthy state and in sickness.

- $\quad$ At the end of the BDS course, the student should be able to manage oral health centers at various levels and in a variety of settings and to work efficiently and effectively in health care teams - in teaching, research and service - making use of the available facilities.
Group 2

- $\quad$ At the end of the learning period, the student should be able to screen patients, identify partially edentulous situations and decide appropriate treatment.

- $\quad$ At the end of the learning period, the student should be able to perform minor surgical procedures such as dental extraction, drainage of an abscess, obtain a biopsy etc.

- $\quad$ At the end of the learning period, the student should be able to demonstrate oral hygiene methods to children below 12 years and perform fluoride application in an attempt to prevent dental caries.

\section{Group 3}

- $\quad$ At the end of the clinical posting, the student should be able to give inferior alveolar block anaesthesia and demonstrate the effect of anaesthesia eliciting signs and symptoms.

- At the end of the lecture, the student should able to enumerate Applegate's rules of applying Kennedy's classification of partially edentulous situations.

- $\quad$ At the end of the clinical posting, the student should be able to make preliminary impressions of completely edentulous patient in three attempts.

The objectives in the first group are broad based and can be an institutional goal. This is related to the needs of the community as a whole and there may not be much difference to this category from nation to nation or from state to state. The second group is of intermediate nature and falls within the institutional objectives. The third group relates to a specific learning activity. They are more precise and can be termed as specific learning objective (Figure 1).

The format of the objective statements used in this article is popularly known as 'Students Will Be Able To' format (SWBAT). Some teachers prefer to frame objectives in 'I can' format. These statements are from a student point of view which encourages the students to identify with the learning goals, visualize themselves achieving the goals and experience a greater sense of personal accomplishment when the learning objectives are achieved. Long descriptive statements are also used to frame learning objective statements.

Citation: K Chandrasekharan Nair., et al. "Role of objectives in Dental Education - A Review". Acta Scientific Dental Sciences 6.2 (2022): 88-94. 


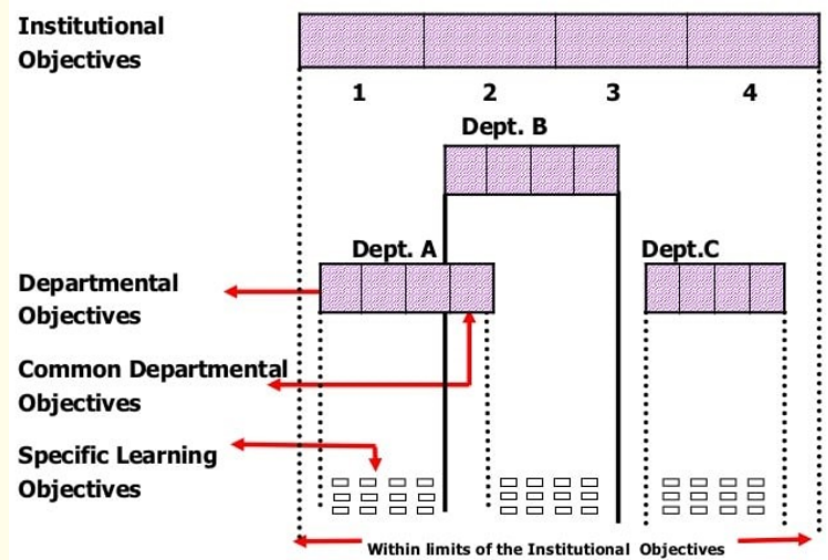

Figure 1. Hierarchy of institutional, departmental and specific learning objectives.

(https://www.slideshare.net/devender1/educational-objectives-110864368)

\section{Qualities of educational objectives}

- $\quad$ Relevant: To the oral health needs of the society and should be convincing to the learner. In India, about $85 \%$ to $90 \%$ of adults have cavities in their teeth because of dental caries. About $30 \%$ of children have misaligned teeth. Over $50 \%$ of Indians with dental health issues receive treatment or advice from someone other than a dentist, such as chemists. About $51 \%$ of Indians use a toothbrush and toothpaste to brush their teeth. Around 28\% brush their teeth the recommended two times a day. Objectives related to dental caries, its prevention through oral hygiene, orthodontic treatment, dentist's role in educating patient will be appealing to the student because of the relevance. In a clinical session if the student is asked to fill up a very long proforma with innumerable number of questions about diseases which are not relevant to India, naturally students will have doubts about the relevance.

- Feasible: Unrealistic objectives should not be set. Years ago, teachers use to tell their students that a doctor has to learn everything under the sun. In those days, teachers enjoyed unquestioned authority and no student dared to ask questions to the teachers. Present day students require very specific instructions and teachers also modified their stand. While formulating educational objectives, requirements like facilities and time should be considered to carry out the instructions.
- Clarity and unequivocality: The words of expression must be precise and should not confuse the student by providing an avenue for multiple interpretations. When a student asks what to study on a particular topic and if an answer is given that you should know everything, the objective loses its clarity. The objective should be unequivocal which means unambiguous, clear having only one possible meaning or interpretation.

- Observability and measurability: The change happening to the student should be observable and measurable; otherwise, evaluation becomes a difficult task.

In the example given above - at the end of the clinical posting, the student should be able to make preliminary impressions of completely edentulous patient in three attempts - all the qualities are incorporated. It is relevant to the profession of dentistry and to the society comprising of so many senior citizens. In a clinical situation it is feasible to test the skill. A trained undergraduate student can perform this without much difficulty. The instruction is clear and there is no scope for multiple interpretations. Before the said clinical posting, the student could not do this but after the clinical posting, the student should be able to make an impression but his proficiency is measured by stipulating a condition that he gets only three chances to prove. If the student is not successful even with three attempts, his grade will be lowered and may be subjected to further training.

Learning objectives precisely articulates the academic expectations of the teachers. When learning objectives are clearly communicated to the students, they are more likely to achieve the presented goals reasonably faster. Conversely, when the learning objectives are absent or unclear, students may not know what's expected of them, which subsequently leads to confusion and frustration and that could impede the learning process.

\section{Uses of educational objectives}

Learning objectives help the teachers to structure, sequence, and plan out learning goals for a specific instructional period, typically for the purpose of directing the students towards the achievement of larger and long-term educational goals that are expected out of the course, performing well on a standardized test, or graduating from the college/university. In short, educational objectives help to develop a teaching learning process and an evaluation process 


\section{Types of objectives}

When a student is enrolled to the BDS programme, he is lead to a desired goal and it will be stated as educational objectives at different levels. One of the objectives of the institution will be to equip the student to manage dental emergencies. The surgery department that handles the emergency will have more focused objectives which state that the student should have knowledge of various types of dental emergencies, the commonest causes and the methods of management. This objective is named as the departmental (intermediate) objective and which falls within the institutional objective. The departmental objective comprises of different specific learning objectives viz. the student should be able to examine a patient who reports with post extraction bleeding, put a suture and apply a compression pack. For achieving this objective, first a lecture can be given followed by a posting in the casualty department, assisting the surgeon and later managing a patient under supervision. The supervisor can evaluate the student on the knowledge by asking questions and on the skill by observation. This is the primary hierarchical pattern of objectives followed in dental colleges of India - 1. Institutional objectives (general) 2. Departmental objectives (intermediate objectives) 3. Specific learning objectives (precise) (Figure 1).

\section{Taxonomy of educational objectives}

Taxonomy of educational objectives is a classification system of different types of educational objectives used for effective understanding and precise communication. The idea for this classification system was formed at an informal meeting of college examiners attending the 1948 American Psychological Association Convention in Boston. At this meeting, interest was expressed on a theoretical framework which could be used to facilitate communication among examiners. This group felt that such a framework could do much to promote the exchange of test materials and ideas about testing. In addition, it could be helpful in stimulating research on examinations and on the relations between examination and education. The original plan of complete taxonomy consisted of three domains viz. - the cognitive, the affective, and the psychomotor. The cognitive domain includes objectives that deal with the recall or recognition of knowledge and the development of intellectual abilities and skills. A second part of the taxonomy is the affective domain. It includes objectives which describe changes in interest, attitudes, and values, and the development of appreciations and adequate adjustment. The third domain is the manipulative or motor-skill area.
More than thirty participants were present in the meeting but the findings were later known after Benjamin Bloom. Educational objectives, thereafter were classified under three domains: Cognitive (knowledge), Psychomotor (skills) and Affective (attitude).

Go through the following objectives

Objectives belonging to the Cognitive domain

- 1a. List five commonly used impression materials.

- $\quad$ 1b. Classify impression materials into elastic and non elastic based on the physical state of the set material.

- $1 c$. Select an appropriate impression material to be used in a partially edentulous situation.

- $\quad 2 a$. List the eruption dates of the permanent teeth.

- $\quad 2 b$. Compare the difference in eruption dates of males and females.

- 2c. Determine the age of a young individual after observing the teeth present.

The above objectives indicate intellectual activity and hence they belong to the cognitive domain. Though they belong to the same domain, there is a hierarchical difference. 1a and 2a belong to the ability to recall facts (knowledge). $1 \mathrm{~b}$ and $2 \mathrm{~b}$ requires an ability to interpret data (comprehension) and $1 \mathrm{c}$ and $2 \mathrm{c}$ require an ability to solve a problem (application). These are all intellectual activities and hence belong to the cognitive domain.

Objectives belonging to the Psychomotor domain

- 1a. Give an inferior alveolar block as the teacher has demonstrated.

- $1 b$. Perform dental extraction on patients attending the oral surgery department under the supervision of the teacher.

- $\quad$ 1c. Control confidently the bleeding from an extraction socket in a patient whose tooth was extracted in another dental clinic.

- 2a. Obtain history of the presenting complaint through an interview (as the teacher did).

- $\quad 2 b$. Instruct a child and mother the correct method of brushing.

- 2c. Speak in the college welfare society on the importance of oral hygiene. 
The above activities require psychomotor activity (skill) of the learner and he is expected to perform a professional skill or a communication skill. The common activities include doing some work either in the clinic/ laboratory or communicating with the patient/ relative of the patient/ colleague. These objectives can be grouped under skills or psychomotor domain. The different levels of this domain are imitation (1a,2a) - here the student primarily imitates the teacher who has demonstrated the skill, practice under supervision $(1 \mathrm{~b}, 2 \mathrm{~b})$ - here the student performs the skill but under the supervision of the teacher and proficiency (1c, 2c) - here the student is allowed to perform independently because the teacher is confident that the student can perform proficiently.

Objectives belonging to the affective domain

- 1 a. The learner would be able to show concern of the anxiety of a patient waiting for dental extraction.

- $\quad 1 b$. The learner would be able to speak a few reassuring words to the patient.

- $1 c$. The learner would habitually comfort patients before a procedure is undertaken.

- $2 a$. Listens to the instructions given by the teacher.

- $\quad 2 b$. Goes to the library and refers books and journals to know more about on what the teacher has instructed.

- $\quad$ 2c. Regularly goes to the library and reads.

These activities are concerned with the human element. The dentist should have a heart to feel, respond with consideration and develop a good nature. The activities described fall under the attitude of the learner or the affective domain. The objectives $1 \mathrm{a}$ and 2 a belong to the category of receiving because the student becomes aware of an idea and is willing to receive it. Objectives $1 \mathrm{~b}$ and $2 \mathrm{~b}$ belong to the category of responding - here the student is expected to respond to the idea he received. Objectives $1 \mathrm{c}$ and $2 \mathrm{c}$ belong to the category of internalization - here the student is habituated to receive ideas and appropriately responding to it.

\section{Specific learning objectives (SLO)}

Our country needs dentists who can provide preventive, interventional and curative measures to maintain oral health of the people. Our dentists should function effectively in a dental team or with other health care professionals in the management and health promotion for all patients. This statement appears laudable but the student will not know what he should do to reach that place. The policy makers of our country know the qualities of dentists we require which are based on the oral health needs of the country and it is broadly communicated to the institutions where training programs are conducted. Based on the disease profile, oral diseases are categorized into different specialties which are represented by the respective departments. Each department will design its teaching programme consisting of lectures, demonstrations, clinical postings, assessment systems, communication methods based on ethical values. A document of departmental objectives will guide the teachers to formulate 'specific objectives' and it will be brought to the notice of the students too. Once the student becomes aware of the objectives of a class, their attention level will improve because they know that the teacher is going to evaluate or assess him at the end of the class, based on the objective.

In order to instruct the student, the institutional and intermediate objectives must be broken down into specific tasks. Each task will have specific educational objectives. The specific objectives will help in designing the instructional method and the evaluation process. This will also help the student to organize himself. The objective must be relevant, unequivocal, observable, measurable and feasible. Specific educational objective can be defined as a task accompanied by criteria indicating an acceptable level of performance.

Specific learning objectives should contain the following four elements:

- Activity - this describes what the learner is expected to do and is normally expressed in terms of an active verb.

- $\quad$ Content - this describes the subject, object or theme in relation to the activity performed.

- Criterion - this describes the acceptable or desirable level of proficiency expected.

- Condition - this describes the important conditions/resources supplied and the restrictions applied, under which the learner should perform.

Go through the following objectives:

- Identify on periapical radiographs of the maxillary and mandibular teeth of a patient, radiolucent lesions in relation to the teeth with hundred percent accuracy.

Citation: K Chandrasekharan Nair., et al. "Role of objectives in Dental Education - A Review". Acta Scientific Dental Sciences 6.2 (2022): 88-94. 
- $\quad$ Find out the vitality of discoloured anterior tooth, using cold and hot stimuli without causing much discomfort to the patient.

- Obtain impression of a completely edentulous maxillary residual ridge using a stock tray and putty silicone impression material within two attempts.

- List from memory, three indications where endosseous implants can be used.

In the examples, the four elements can be identified:

- Activity-identify/find out/obtain/list

- Content-radiolucent lesions/vitality/impression/indications

- $\quad$ Condition - peri apical radiographs of the patient

- $\quad$ Cold and hot stimuli

- $\quad$ Stock tray and putty silicone

- Implants

- Criterion: hundred percent accuracy/without discomfort/ two attempts

- $\quad$ Three indications

The criteria help in the assessment without any ambiguity.

In these examples, the qualities of SLO can also be found out.

- $\quad$ Activity guides us to the skill or behavior change expected in the learner.

- Content guides us to the topic or subject matter.

- Criteria guide us how to assess the outcome and what level of competence is expected of the learner.

- $\quad$ Condition guides us to the nature of restrictions to be posed or resources to be provided during the assessment.

However, it is difficult to formulate SLO for the affective domain for reasons of measurability and observability. Students learn from their teachers, the right attitude the dentist should have, through the model behavior of the teacher. Student - patient interactions in the clinic can be assessed by the teachers using rating scales.

When developing learning objectives, it is desirable to consider the following questions:

- $\quad$ For whom are the objectives framed and what is their previous knowledge?
- Will I get adequate time to achieve the objectives?

- What level of mastery I expect the students to achieve?

- How will students demonstrate mastery?

- Will the mastery be observable and measurable?

- In short is the objective Specific, Measurable, Achievable, Relevant and Time bound?

\section{Conclusion}

While designing the course, it should be made sure that internal structure should be strong and conducive to the student learning. Articulate the objectives in precise terms on the knowledge, skills and attitudes which are expected from the students at the end of the course. Assessments are done to check the degree to which the students are meeting the learning objectives. Instructional strategies are chosen to foster student learning towards meeting the objectives. Aligning these three components viz. objectives, assessments and instructional strategies is never static but a dynamic process because the world is progressing by doubling the knowledge overnight (Figure 2). When these components are not aligned, students might complain that the test did not have anything to do with what was covered in class, or instructors might feel that even though students are earning a passing grade, they haven't really mastered the material at the desired level.

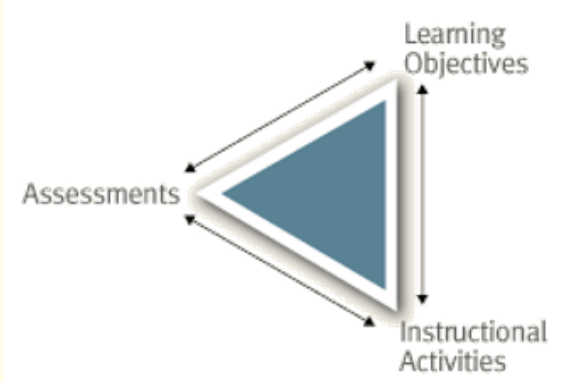

Figure 2. Objectives, instructional activities and assessment. (https://www.cmu.edu/teaching/designteach/design/learningobjectives. html)

\section{Bibliography}

1. Guilbert JJ. "Educational handbook for health professionals". WHO offset publication No. 35, Geneva, WHO (1987).

2. Bloom BS. "Taxonomy of educational objectives". Hand book I - cognitive domain, David Mckay Company, New York (1956). 
3. Harrow A J. "A taxonomy of psychomotor domain". David Mckay Company, New York (1972).

4. Krathwohl. "Taxonomy of educational objectives". Hand book II - Affective domain, David Mckay Company, New York (1964).

5. Anathakrishnan N., et al. "Medical education - principles and practice". ( $2^{\text {nd }}$ ed), National teacher training centre, JIPMER, Pondichery, India 9-26.

6. https://borgenproject.org/issues-of-dental-health-in-india/

7. https://www.edglossary.org/learning-objectives/

8. https://rae.medicine.wisc.edu/developing-learning-objectives

\section{Assets from publication with us}

- Prompt Acknowledgement after receiving the article

- Thorough Double blinded peer review

- Rapid Publication

- Issue of Publication Certificate

- High visibility of your Published work

Website: www.actascientific.com/

Submit Article: www.actascientific.com/submission.php

Email us: editor@actascientific.com

Contact us: +919182824667 